\title{
Redes de segurança alimentar e agricultura familiar: a merenda escolar como instrumento de desenvolvimento local
}

\author{
Luiz Fernando Paulillo ${ }^{1}$ Luiz Manoel de Almeida ${ }^{2}$
}

\begin{abstract}
O trabalho apresenta um caso concreto de formação de uma rede de capital social em torno da temática da segurança alimentar local, abarcando não somente as condições de saúde das pessoas, de higiene dos alimentos e da autenticidade da produção, mas também a melhora das condições de renda e emprego de pequenos agricultores e trabalhadores rurais. Este trabalho mostra que num município paulista foi possível desenvolver um programa de segurança alimentar ${ }^{3}$ com essa amplitude, através da inclusão do suco de laranja natural pasteurizado na merenda escolar. Este caso, ocorrido no centro do cinturão citrícola brasileiro, mostra como mecanismos institucionais desenvolvidos por meio de políticas públicas participativas e organizações locais podem promover o desenvolvimento rural local com possibilidades de inclusão social.
\end{abstract}

Palavras-chave: Políticas públicas, citricultura, segurança alimentar, merenda, capital social.

\section{Food security-safety systems and family agriculture. The School Lunch Program as a tool for local development}

This paper shows a concrete case of social capital networking related to the theme of local food safety. The position taken is that food safety should be treated on a wider scale, including not just the health conditions of people, food hygiene and the authenticity of the product, but the improvement of salaries and working conditions of small producers and rural workers as well. This study shows that Bebedouro, a city of the State of São Paulo, where a food safety program of such broad scope was carried out, pasteurized natural orange juice was introduced in school lunches. This case report, materialized in the center of the Brazilian citrus territory, demonstrates that by activating institutional mechanisms, participative public policies and local organizations, rural development can be promoted with the possibility of producing social inclusion.

Keywords: Institutional, food safety, social capital networking.

\section{Sistemas de Seguridad Alimentaria y agricultura familiar. La Merienda Escolar como instrumento de desarrollo local}

Resumen: El trabajo presenta un caso concreto de formación de una red de capital social al rededor de la temática de la seguridad alimentar local. Tomo como principio que la seguridad alimentar

\footnotetext{
${ }^{1}$ Doutor em Economia - Instituto de Economia/UNICAMP. Professor Adjunto do Departamento de Engenharia de Produção da Universidade Federal de São Carlos.

${ }^{2}$ Doutor em Sociologia - Faculdade de Ciências e Letras de Araraquara/Universidade Estadual de São Paulo. Mestre em Engenharia de Produção - Universidade Federal de São Carlos.

${ }^{3}$ O projeto intitulado "Frutos da Vida" foi criado e desenvolvido pela prefeitura de Bebedouro - SP no segundo semestre de 2002 e teve sua consolidação nos anos de 2003 e 2004. O principal objetivo do referido projeto foi instituir um programa de segurança alimentar a partir da formação de uma rede de suprimento de suco pasteurizado natural de laranja para as merendas das creches e escolas municipais e estaduais do município, sendo a fruta adquirida de pequenos produtores locais, colhida por trabalhadores rurais registrados, recebendo salários dignos e cursos de qualificação, processada em uma pequena unidade industrial do município e embalada e distribuída pela central municipal de alimentos. Todo esse processo, desde a colheita da fruta ao copo das crianças durava, no máximo, dois dias. O programa envolveu cursos de capacitação para trabalhadores rurais e para as merendeiras das escolas envolvidas
} 
debe ser tratada de manera amplia, de forma a abarcar no solamente las condiciones de salud de las personas, higiene de los alimentos y autenticidad de la producción, mas también la mejora de las condiciones de renta y colocación de pequeños agricultores y trabajadores rurales. Este trabajo muestra que en un municipio paulista se desarrolló un programa de seguridad alimentar en esa amplitud, con la inclusión del jugo de naranja natural pasteurizado en la merienda escolar. Este caso, ocurrido en el centro del cinturón citrícola brasileño, muestra cómo mecanismos instuticionales desarrollados a través de políticas públicas participativas y organizaciones locales pueden promover el desarrollo rural local con posibilidades de inclusión social.

Palabras clave: Instituciones, seguridad alimentar, red de capital social.

\section{Introdução}

A segurança alimentar deve ser tratada de maneira ampla (abarcando não somente as condições de saúde das pessoas, de higiene dos alimentos e da autenticidade da produção, mas também a elevação das condições de renda e emprego de pequenos agricultores familiares e trabalhadores rurais envolvidos com a produção alimentar). $\mathrm{O}$ presente trabalho mostra que, no município de Bebedouro-SP, a prefeitura local desenvolveu um programa de inclusão do suco de laranja natural pasteurizado na merenda escolar durante o período 2002/2004. O resultado mais promissor foi o início da formação de uma rede de capital social local, envolvendo pequenos citricultores do município, trabalhadores rurais com direitos trabalhistas garantidos, uma pequena processadora de suco de laranja, órgãos e agências públicas municipais, universidade pública e entidades civis locais. Com a apresentação desse estudo de caso, o trabalho pretende mostrar como mecanismos institucionais desenvolvidos através de políticas públicas participativas e organizações locais podem promover o desenvolvimento rural local com possibilidades de inclusão social (neste caso, de pequenos citricultores e trabalhadores rurais da citricultura), com a cristalização (embeddedeness) de uma rede de capital social (envolvendo características sociais positivas dos indivíduos - cooperação, transparência, reputação, legitimidade - e características positivas das relações sociais em rede - freqüência, intensidade, velocidade etc.). O item 2 discorre sobre a problemática da reestruturação agroindustrial no Brasil e as possibilidades de formação de redes de segurança alimentar local. O item 3 enfatiza os reais caminhos da formação de redes ocorrer por meio de políticas públicas municipais. O item 4 trata do desafio da cristalização (embeddedeness) do capital social em torno do tema da segurança alimentar no Brasil. O item 5 evidencia o grau de concentração da agroindústria citrícola no Estado de São Paulo e as possibilidades de colocação do suco no mercado institucional. O item 6 mostra a implementação bem sucedida de uma rede de segurança alimentar local no município de Bebedouro - SP. O trabalho finaliza considerando as principais possibilidades de formação de novas redes de segurança alimentar local diante da reestruturação agroindustrial de caráter global.

\section{A reestruturação agroindustrial no Brasil e a necessidade da formação de redes de segurança alimentar local}

No final do Século XX a abertura comercial, a fragmentação do Estado, a complexidade da sociedade civil e o predomínio de políticas econômicas voltadas para a estabilização monetária aumentaram as desigualdades sociais e alargaram a distância entre as pessoas nutridas e desnutridas no mundo. Uma sinalização forte desse distanciamento é o crescimento da sofisticação dos hábitos alimentares dos nutridos (garantida pela maior oferta e qualidade dos produtos das grandes cadeias agroindustriais) e, ao mesmo tempo, a precariedade ou a falta de alimentação para centenas de milhões de pessoas.

Estas pessoas continuam à margem do sistema capitalista, mesmo nos países em desenvolvimento que apresentaram resultados de crescimento relativamente satisfatórios nos últimos trinta anos. No Brasil existem cerca de 23 milhões de brasileiros desnutridos, segundo a FAO (Paulillo, 2002). Mas essa quantidade é significativamente superada se a linha de indigência for a ingestão mínima diária de $2000 \mathrm{kcal}$ por pessoa (a quantidade mínima necessária à manutenção saudável de uma vida produtiva). 
No cerne do distanciamento entre as pessoas nutridas e desnutridas está o processo de reestruturação agroalimentar global, do qual a sofisticação dos hábitos alimentares dos nutridos é apenas uma das faces. Friedman (2000, p. 19) observou que o modelo liberalprodutivista cultivou o gosto pelo alimento industrializado entre os consumidores urbanos e organizou as matérias-primas e os mercados em escala cada vez maior, ao mesmo tempo em que ocorreu o abalo do poder de regulação dos Estados Nacionais. Este abalo, que não deixou "espaços vazios" para o renascimento das forças invisíveis do mercado (Bonanno, Marsdem e Silva, 1999, p. 357), permitiu que as grandes empresas agroindustriais assumissem a coordenação dos setores alimentares oligopolizados. Tal procedimento desencadeou um novo ritmo para o processo de concorrência agroindustrial porque as grandes cadeias produtivas de alimentos avançaram no mundo através da intensificação dos processos de integração vertical e de quase-integração das grandes empresas de processamento, de flexibilização da produção, do aprimoramento dos modos de distribuição e consumo, da marginalização de produtores e trabalhadores rurais etc.

Neste contexto, a obsessão das políticas econômicas nacionais pela estabilização monetária faz com que a segurança alimentar da população seja vista de maneira muito conservadora. Não basta elevar a oferta de alimentos e conter a inflação como não basta garantir uma renda mínima individual. As grandes cadeias produtivas já podem eliminar a fome mundial. São produzidos diariamente no mundo três quilos de alimento por pessoa. A existência de políticas de não produzir na agricultura (tipo set-aside) é o melhor exemplo da suficiente oferta de alimentos nos países desenvolvidos. Entretanto, o problema da fome persiste em boa parte do globo. Enquanto Europa, Oceania e América do Norte reduziram fortemente suas escalas de miséria, concentradas atualmente nos grupos de imigrantes clandestinos e nas minorias (tipo as tribos aborígines na Austrália), África (com 21,7\%) e Ásia (com $63 \%$ ) concentram $84,7 \%$ da população de desnutridos do mundo (Paulillo, 2002).

Nos continentes asiático e africano a fome é resultado da ausência de alimentos. Mas existem países em que a fome é o resultado da extrema desigualdade social (faltam renda mínima, educação mínima, informação mínima e empregos dignos para uma parte da população). O Brasil enquadra-se no segundo grupo. Desde os anos 70, o país vem elevando sua produção de alimentos com sucessivos recordes de safra, porém a desigualdade social só aumentou. No caso da desigualdade de renda, em 2000 a distância entre a renda dos $20 \%$ mais pobres e a dos $20 \%$ mais ricos do Brasil foi de 33 vezes, segundo o IPEA (Instituto de Pesquisas Econômicas Aplicadas). Os 20\% da população brasileira mais pobre recebem apenas $2 \%$ da renda, segundo o Banco Mundial. Como comparação, o percentual é de 3,1\% na Argentina e de 4\% na Bolívia.

Entretanto, o acesso à renda mínima individual não garante a segurança alimentar de um povo. No curto prazo ela é bem-vinda, porém no longo prazo a renda mínima poderá se tornar o norte de um programa exclusivamente assistencialista, viciando ainda mais um sistema de perfil concentrador, desigual e excludente, do qual a redução ou precariedade do emprego e a escassez de saúde, educação e informação das pessoas são os principais resultados ${ }^{4}$.

A segurança alimentar vai além do acesso à renda porque deve ser reconhecida como um recurso fundamental de inclusão social. Isso significa fazer com que as camadas sociais marginalizadas tenham acesso a recursos básicos da vida em sociedade (como emprego, educação, saúde, informação etc.) e possam participar das decisões que afetam suas vidas. Este último aspecto é muito importante porque, com o avanço da globalização e a fragmentação do Estado, as agendas de decisões relevantes (em setores produtivos ou não produtivos) estão cada vez mais distantes e fechadas para grande parte dos empreendedores e trabalhadores. Em algumas redes de orquestração de interesses estão fechadas até mesmo para os governantes. Exemplos significativos existem nos setores do agronegócio brasileiro (as grandes cadeias de produção agroindustrial), em que a grande parte dos agricultores, empresários industriais, prestadores de serviços e trabalhadores estão cada vez mais distantes das agendas de decisões que afetam suas vidas.

Entretanto, muitas dessas decisões podem se dar em nível local, mesmo que seja em redes de poder que operam no interior dos fluxos agroalimentares

\footnotetext{
${ }^{4}$ No caso da agricultura, o processo de exclusão social não atinge somente os trabalhadores, pois muitos pequenos proprietários agrícolas tornaram-se marginalizados das grandes cadeias produtivas, enquanto outros abandonaram suas propriedades rurais.
} 
globalizados. Ou seja, é possível a operação de redes de inclusão social nos territórios pelos quais as grandes redes agroindustriais passam. Sabe-se que, no Brasil, esses fluxos agroalimentares globalizados que atravessam o país criaram complexos agroindustriais e redes políticas que causaram a marginalização de boa parte das pessoas produtivas (no campo, na indústria, no setor de serviços etc.), ao mesmo tempo em que se acentuou a integração dos capitais financeiro, industrial, comercial e agrário.

Alguns exemplos de movimentos locais orquestrados para a formação dessas redes de poder de inclusão social podem ser citados, como: 1) associações de agricultores para venda de produtos no comércio justo internacional (redes fair trade); 2) grupos de agricultores familiares com produção dirigida ao mercado institucional nacional (merendas das escolas municipais e estaduais, hospitais, creches, penitenciárias etc.); 3) governos municipais com gestão participativa em áreas rurais e urbanas; 4) cooperativas ou consórcios de produtores e trabalhadores rurais visando a melhorias das administrações e comercializações das produções rurais e garantias dos direitos trabalhistas; 5) câmaras setoriais pluralistas e comitês de bacias hidrográficas com participação elevada de atores sociais etc.

A construção social de baixo para cima com o foco na inclusão social é o processo mais importante e inovador de tais redes organizadas localmente. Esses aspectos assumem especial importância quando se pretende focar lugares (municípios ou regiões) que possam alcançar a segurança alimentar e, ao mesmo tempo, se adaptar ao intenso processo competitivo dos fluxos agroindustriais globalizados sem abandonar o foco da eqüidade social. A inclusão social pode atingir esses ambientes de produção agrícola e alimentar e se tornar um dos eixos fundamentais de um programa de segurança alimentar, pois é nos municípios agrícolas e agroindustriais que existe a possibilidade do envolvimento de pequenos agricultores em situações de marginalização dos mercados tradicionais e de trabalhadores em situações de precarização profissional e social. Assim, a prioridade da segurança alimentar não recai apenas na demanda (com a alimentação adequada para a criança, o idoso, os doentes etc.), devendo alcançar também a oferta (com as novas possibilidades de venda dos alimentos de pequenos agricultores e fabricantes de alimentos do município ou região).
Desta forma, um programa de segurança alimentar pode potencializar o desenvolvimento local com inclusão social.

A presença das grandes cadeias agroalimentares em uma região não garante a eliminação da fome e muito menos o início do processo de cristalização (embeddedeness) da segurança alimentar. Para isso é necessário que cada indivíduo possa encontrar trabalho, educação, renda, informação mínima etc., e também participar das agendas de decisões sobre tais temas. Além do mais, os distintos setores que geram renda não podem aprofundar ainda mais as desigualdades econômicas que ameaçam a estabilidade social - especialmente as cadeias agroindustriais, que geram renda e produzem alimentos.

Trata-se, portanto, de um conceito de inserção social que deve permear a constituição de redes locais de segurança alimentar, onde a complexidade da reestruturação agroindustrial nos países, com seus impactos na insegurança alimentar das pessoas, é um grande problema. Ou seja, reestruturação agroindustrial global e segurança alimentar local estão imbricadas. Para o Brasil, o presente problema deve ser analisado sob uma particularidade relevante, pois como Celso Furtado mostrou, a formação econômica brasileira foi heterogênea em termos estruturais, tecnológicos e regionais. Isso é fundamental para tentar resolver qualquer distorção social do país dependente da elaboração e efetivação de políticas públicas. Assim, o âmbito local deve se tornar o espaço de realização de políticas públicas de segurança alimentar.

Sabe-se que a reestruturação agroalimentar no Brasil não é homogênea porque cada complexo agroindustrial do país revela uma dinâmica específica. Isso é acentuado com as particularidades das regiões. $\mathrm{Na}$ história de cada lugar não está apenas o desenvolvimento de produções agrícolas e agroindustriais locais, está a cultura regional e o hábito alimentar local. Assim, nos lugares convivem simultaneamente instituições eminentemente locais e instituições específicas de cada complexo agroindustrial que pelo lugar atravessa (com regras, normas, convenções e relações de poder agroindustriais específicas). Isso tudo faz com que a operação das políticas agroalimentares requeira soluções diferenciadas, desde que não sejam eminentemente setoriais e que incluam, em sua maior parte, elementos locais. 


\section{Segurança alimentar e políticas públicas: o viés local é possível!}

A segurança alimentar se desenvolve ao redor de novos valores socialmente construídos e compartidos, como a nutrição e a saúde das pessoas, a sustentabilidade do meio ambiente, a autenticidade da produção do alimento etc. O objetivo dessa construção é alcançar a funcionalidade e a adaptação de um padrão alimentar com eqüidade para a população. Isso significa introduzir valores solidários nas esferas do consumo e da produção alimentar. Assim, a noção de segurança alimentar é ampla e abrange todos os segmentos que produzem e distribuem alimentos (agricultura, indústria, serviços e comércio), sendo determinada por cinco eixos.

O primeiro é o da noção de saúde, com suas dimensões dietética e farmacêutica, ambas ligadas à composição nutricional dos alimentos (o conteúdo protéico, de fibras, colesterol etc.). Para tal, a educação alimentar da população carente é fundamental.

O segundo eixo é o da higiene dos alimentos, com a ausência dos elementos tóxicos e nocivos às pessoas. Essas noções estão indissociavelmente ligadas à necessidade de informação, de garantias e controles sobre as condições de produção e distribuição dos alimentos, e sobre as normas de embalagem. Enfim, as normas, fiscalizações e certificações dos produtos alimentares são cruciais.

O terceiro eixo é o ecológico, que corresponde à produção de alimentos sem riscos tóxicos e à reivindicação do respeito ao meio ambiente, porque a demanda alimentar concerne tanto à qualidade do alimento quanto à maneira de produzi-lo, e a ecologia é um valor crescente nos hábitos de vida da população. Tanto que, nos países desenvolvidos, há relevantes movimentos de apoio dos consumidores pela preservação do meio ambiente.

O quarto eixo é o da autenticidade, que se refere aos valores tradicionais da produção agroalimentar, à valorização da origem dos produtos e às especificações dos processos produtivos da agricultura e da indústria alimentar. Enfim, são os ideais do saber fazer.

O quinto eixo é o da solidariedade, no qual os valores morais e ideológicos impulsionam as participações da população bem nutrida e dos governantes em ações humanitárias no processo de consumo, através da compra de um produto socialmente correto em vez de outro. Nestes casos, o preço a ser pago pelo produto pode até ser mais elevado porque privilegia a produção agrícola marginalizada (de assentamentos rurais, pequenas propriedades familiares, propriedades com ausência da mão-de-obra infantil etc.). Muitos exemplos existem, como o comércio justo internacional ou os mercados institucionais municipais, que estão crescentemente sendo utilizados por atores sociais imbuídos do intuito de cristalizar o eixo solidariedade da segurança alimentar no mundo capitalista.

As ações do tipo food security (quantidade alimentar) e food safety (qualidade alimentar) estão contempladas em todos esses eixos. São diversas acepções de segurança alimentar que associam, em graus diversos, a qualidade substancial ou física dos produtos (composição nutricional, grau de toxidade, quantidade de calorias, propriedades gustativas etc.) e sua qualidade institucional (levando em conta os efeitos provocados pelos processos de produção e de comercialização alimentar no meio ambiente e no contexto social). Assim, existe um componente da demanda que abarca a qualidade externa e que se refere, portanto, às dimensões política, cultural e social da qualidade alimentar.

Nos países desenvolvidos, por detrás da demanda de produtos verdes se encontra o refute de um sistema de valores que tem permitido a exploração ilimitada da natureza (Arce e Marsden, 1994, p.7-8). A demanda da qualidade alimentar se acompanha da exigência de definições claras e de garantias referentes aos produtos agroindustriais, que, como foi dito, ultrapassam a questão da qualidade física dos alimentos e abrangem aspectos políticos e culturais de cada setor ou região produtiva (Paulillo \& Pessanha, 2002).

No Brasil, muitos complexos agroindustriais formaram-se através dos avanços dos circuitos produtivos globais e as demandas das regiões nacionais de origem tiveram importância secundária. Enfim, os circuitos regionais não foram o alvo agroindustrial prioritário e a questão da segurança alimentar local (em regiões e municípios) não foi privilegiada.

Em países com maior dimensão territorial e grau de diferenciação interna como o Brasil, a segurança alimentar também deve ser pensada em termos 
regionais, de modo a adensar os circuitos produtivos e distributivos locais, captar hábitos alimentares diferenciados, reforçar a diversificação produtiva e abrir espaços aos pequenos e médios empreendimentos (rurais e urbanos) e aos agricultores em exclusão (Maluf, Menezes \& Valente, 1996, p. 85).

A existência de cadeias agroindustriais regionalizadas faz com que a implementação de redes organizacionais de segurança alimentar seja facilitada. É o que torna possível a execução de medidas do food security e do food safety de cunho localizado, pois a segurança alimentar pode ser o tema de uma rede de orquestração de interesses (policy network). Isto é, uma rede de segurança alimentar pode articular em torno de si um conjunto de empresas, associações de interesses, organizações não governamentais, cooperativas, agricultores, agências públicas estatais, prefeituras municipais, universidades, centros de pesquisa etc. São as redes políticas locais que podem conceber soluções de segurança alimentar de modo singular e específico em cada região.

No âmbito territorial, surgem novas estruturas de oportunidades, porque os governos e os atores sociais aí estabelecidos redefinem seus papéis. Isso ocorre por meio da adaptação estratégica dos atores locais (fixo) ao espaço global (fluxos). Sauborin (2002, p.3) alega que:

“... um território não consiste simplesmente em atributos naturais. Ele é construido segundo a capacidade dos atores de estabelecer relações organizadas - mercantis e não mercantis que favoreçam não só a troca de informações e a conquista de certos mercados, mas também a pressão coletiva pela existência de bens públicos e de administrações capaz̨es de dinamizar a vida regional..".

A mobilização do capital social local refere-se à capacidade de estabelecer a organização do território ou comunidade por intermédio de normas de confiabilidade entre os agentes, de forma que se possa melhorar a condição da sociedade por meio de ações coordenada em redes (Putnam, 1996, p.167). Paulillo (2002, p.45) mostra que os fatores que permitem a mobilização do capital social local são os seguintes: a) estabelecimentos de normas; b) estoque de capital social (ou recursos de poder); c) cooperação voluntária; d) confiança e; e) reciprocidade.

\section{O embeddedeness (cristalização) da segurança alimentar local}

As construções dos valores do food safety e do food security referem-se às experiências econômicas e sociais, repletas de significados culturais e ações políticas específicas. Qualidades físicas dos produtos alimentares são essenciais para o alcance de um estágio mínimo de segurança alimentar. Entretanto, as qualidades institucionais (como normas adequadas para o funcionamento de um programa de política pública, a coordenação e a fiscalização de programas de segurança alimentar do tipo bolsa-família, bancos de alimentos, alimentação escolar e outros, a continuidade de parcerias entre prefeituras e empresas para o financiamento de programas de erradicação do analfabetismo, do primeiro emprego, de capacitação de trabalhadores rurais, de redução da fome etc.) também são fundamentais. Qualquer rede ou organização constituída em torno do tema segurança alimentar necessita destes quesitos institucionais.

Nesta perspectiva, os processos de construção da segurança alimentar podem produzir, nos lugares, o desenvolvimento do capital social local. Putnam (1996, p. 167) define capital social como um conjunto de fatores de organização social (como confiança, reputação e legitimidade de pessoas e grupos, assim como normas, reciprocidade, intensidade e velocidade das relações) que possam melhorar o bem-estar da sociedade através de ações coordenadas facilitadas.

Monasterio (2001) cita Putnam (2000) para destacar três modalidades de capital social (todas elas baseadas na posição social dos indivíduos):

1) bonding social capital (envolve os vínculos entre agentes da mesma posição) - são os grupos homogêneos, voltados para dentro, nas quais as identidades dos membros são reforçadas e úteis para a resolução de problemas de ação coletiva e para apoio mútuo intra-grupo (Putnam, 2000, p. 23);

2) bridging social capital (são os laços fracos entre os agentes de grupos sociais distintos) - são relações sociais mais distantes que transpassam as fronteiras sociais, nas quais as virtudes cívicas se mostram entre indivíduos com distintas situações étnicas, ocupacionais e demográficas, em que pode decorrer uma sociedade fluída e integrada, na qual, por exemplo, a despeito das diferenças sociais, 
pobres e ricos confiam uns nos outros e compartilham informações (Monasterio, 2001, p. 516);

3) linking social capital (refere-se às ligações verticais entre pobres e pessoas em postos de decisão em organizações formais): são relações em que é possível florescer redes e comunidades que tenham governos permeáveis às demandas oriundas dos estratos inferiores da pirâmide social (Monasterio, 2001, p. 516).

O estabelecimento do capital social nas modalidades bridging social capital (laços fracos entre atores de grupos distintos) e linking social capital (laços verticais entre pobres e agentes decisórios de organizações formais) é o maior desafio para a cristalização da segurança alimentar local. Monastério (2001, p. 516) argumenta que, especialmente nos países não desenvolvidos, os mais desfavorecidos têm acesso a elevados estoques de bonding social capital, pouco bridging, e quase nenhum linking. Isto é, apesar da coesão entre os pobres permitir a existência do apoio mútuo em diversas situações, existem dificuldades para as intensificações das relações entre pobres e organizações executoras de políticas públicas, fazendo com que os governos atendam muito pouco as demandas da população de baixa renda. Nessas situações de carência de capital social dos tipos bridging e linking, a população não participa ou pouco participa da vida pública (sociedade pouco cívica), a eficiência do setor público é menor e este é mais permeável às pressões de grupos de interesse.

É neste contexto de efetivação de uma sociedade pouco cívica que as redes de relações necessitam se organizar localmente em torno de um tema específico como o da segurança alimentar. E o processo de cristalização da segurança alimentar não ocorrerá no curto prazo porque há carência de capital social, seja bridging seja linking. Além do mais, o início do processo só poderá ocorrer por iniciativa governamental.

Com a carência do capital social linking, a iniciativa do governante em nível municipal poderá facilitar a formação de uma rede de segurança alimentar. Ou seja, as relações de proximidade entre governo e cidadãos deverão contar significativamente para a cristalização da segurança alimentar em um município. Atores públicos municipais, especialmente do poder executivo, podem exercer papéis relevantes nos processos de coordenação de redes de segurança alimentar, através do estabelecimento de políticas públicas cujo objetivo seja o de potencializar as características das conexões em rede. Isto é, implementar regras mais claras e adaptadas à realidade local, facilitar a intensidade das relações dos atores envolvidos, expandir a velocidade dos programas e seus resultados, explorar a centralidade nas decisões para correções de etapas e metas dos programas, formalizar acordos necessários etc.

Com estas ações é possível cristalizar nos atores envolvidos em uma rede de segurança alimentar algumas características importantes que facilitarão o desenvolvimento do linking capital social, como a legitimidade das ações, reputação e cooperação entre os atores, grau de informação ou conhecimento e outras habilidades para as conexões ocorrerem ${ }^{5}$.

Nesta perspectiva, processos políticos de inclusão social relacionados à conduta de esquemas de metas passam a ser um fator importante e inovador de tais redes organizadas localmente. Esses aspectos assumem especial importância quando se pretende focar lugares (municípios ou regiões) que possam alcançar a segurança alimentar e, ao mesmo tempo, se adaptar ao intenso processo competitivo dos fluxos agroindustriais globalizados sem abandonar o foco da eqüidade social.

O capital social não é, como às vezes é descrito, um raro tesouro cultural transmitido de uma geração a outra, uma coisa que, caso seja perdida, nunca poderá ser recuperada. Ao contrário, ele é construído em um movimento continuado por indivíduos e organizações. $\mathrm{Na}$ verdade, o capital social torna-se mais importante à medida que a tecnologia avança, as organizações achatam suas estruturas gerenciais e redes substituem hierarquias na estruturação dos negócios (FukwyamaFukuyama, 2002).

O conceito de capital social vem sendo há algum tempo discutido por cientistas sociais nas mais diversas áreas. Putnam (1996, p. 167) visualizou o

\footnotetext{
5 Segundo Paulillo (2002), modificando a versão de Dowding (1995), as características mais importantes dos membros de uma rede de poder são informação, legitimidade, reputação, cooperação e habilidades de conseguir recursos; e as características mais relevantes das conexões em rede são centralidade, intensidade e velocidade e regras claras e aceitas.
} 
capital social como um conjunto de associações horizontais entre pessoas que cooperam para o benefício mútuo da comunidade, as quais são regidas por um conjunto de fatores de organização social, como confiança, reputação e legitimidade de pessoas e grupos, assim como normas, reciprocidade, intensidade e velocidade das relações que possam melhorar o bem-estar da sociedade através de ações coordenadas facilitadas. Putnam (2000) considerou que as evidências históricas indicam que os fatores sócio-culturais, como tradições cívicas, capital social e práticas colaborativas, têm papel decisivo na explicação das diferenças regionais e importância nas estratégias de desenvolvimento local.

Em sua concepção não é possível que se crie ou se forme capital social em locais onde estejam ausentes condições histórico-culturais. Argumentos que vão além dessa visão dizem que os sistemas sociais não são influenciados somente por questões culturais, mas também por componentes sociais, onde os agentes podem promover mudanças e alternativas de "rotas" no processo de desenvolvimento. Tais modificações ou rupturas podem provocar alterações nas relações sociais, permitindo a institucionalização de novos códigos culturais e práticas sociais que promovam a formação de capital social. Além deste, há o argumento de que o Estado cumpre uma função importante para a formação do capital social, com vários estudos, principalmente no campo do neo-institucionalismo, demonstrando a importância do Estado para o desempenho da função "coercitiva" ou "protetora" das relações sociais geradoras de capital social (Castilho, 2001).

Os sociólogos Bourdieu (1980) e Coleman (1990), na discussão de capital social, analisam como indivíduos inseridos em uma rede de relações sociais podem se beneficiar de sua posição ou gerar externalidades positivas para outros agentes. Ampliaram esta conceituação ao incluir relações verticais, caracterizadas por relações hierárquicas e distribuição desigual de poder.

A base dessa explicação pode ser complementada a partir do campo teórico da Sociologia Econômica. Desta ótica, as relações econômicas estão imersas em redes de relações sociais, fundamentadas no poder estabelecido pela confiança recíproca, tanto para o desenvolvimento das interações de mercado, quanto para o estabelecimento de laços sociais mais abrangentes.
No presente trabalho, o capital social está sendo discutido com foco nas instituições. Significa relações sociais "institucionalizadas" na forma de normas e redes sociais. Estas relações são institucionalizadas porque representam acúmulos de práticas sociais culturalmente incorporadas na história de grupos, comunidades ou classes sociais (Castilhos, 2001).

Portanto, capital social envolve o conjunto de recursos que um indivíduo ou grupo pode obter a partir de sua posição em uma rede de relações sociais estáveis. Corresponde ao tecido social ou à cola invisível que mantém a coesão das sociedades e está baseado na confiança entre as pessoas e na rede de relacionamentos entre elas e os grupos sociais que formam as comunidades.

"Rede Social é uma relação moral de confiança de um grupo de agentes individuais que têm em comum normas ou valores além daqueles necessários às transacões habituais de mercado. As normas e os valores abrangidos nesta definição podem ir da simples norma de reciprocidade entre dois amigos até os complexos sistemas de valores criados por religiões organizadas" (Fukuyama, 2002, pg.210).

Esta nova coordenação, definida como rede, baseia-se em normas ou valores comuns que permitem aos indivíduos trabalhar em conjunto para fins comuns.

Por outro lado, uma rede é diferente de uma hierarquia porque se baseia em normas comuns informais, não numa relação formal de autoridade. Entretanto, uma rede pode coexistir com uma hierarquia formal de autoridade. Os membros de uma hierarquia formal não precisam dividir entre si normas e valores além de contratos de trabalho que definem sua participação. Entretanto, as organizações formais podem estar superpostas com redes informais de vários tipos, baseadas em clientela, etnia ou numa cultura corporativa comum. O enfoque institucional de capital social reconhece que a capacidade de grupos sociais de agir para seu interesse coletivo depende crucialmente da natureza e extensão do seu relacionamento com as instituições formais.

Fukuyama, (2002, p. 211) considera que quando as redes estão superpostas no topo de organizações formais, os resultados não são necessariamente benéficos e, na verdade, podem ser fonte de muitas 
deficiências organizacionais. Todos conhecem as redes baseadas em parentesco, classe social, amizade, amor ou qualquer outro fator. Os membros dessa rede têm em comum as normas e os valores importantes, particularmente a reciprocidade, com outros membros da organização. Dentro dessa rede as informações passam rapidamente, mas seus limites externos constituem membrana através da qual as informações transitam devagar. As redes desse tipo são problemáticas e, com freqüência, subvertem as relações formais de autoridade.

A importância do capital social numa organização hierárquica pode ser entendida em termos da maneira pela qual as informações nela se deslocam. Elas podem ser extremamente difíceis e dispendiosas para produzir, mas uma vez existentes, as cópias adicionais são gratuitas. Isto significa que qualquer informação gerada dentro de uma organização, deve em teoria fluir livremente para todas as partes da mesma onde poderá ser de utilidade (Fukuyama, 2002).

O capital social é importante para determinados setores e certas formas de produção complexa precisamente porque as trocas baseadas em normas informais podem evitar os custos de transação interna das grandes organizações hierárquicas, bem como os custos das distantes transações externas. A necessidade de trocas informais e baseadas em normas torna-se mais importante à medida que bens e serviços tornam-se mais complexos, difíceis de serem avaliados e diferenciados ${ }^{6}$ (Fukuyama, 2002).

Araújo (2003, p. 33-38) enfatiza o papel da confiança para a prosperidade das redes. Aponta diferenças na participação associativa a que se refere como "sociabilidade espontânea", em contraste com as sociedades cuja sociabilidade se dá por estruturas hierárquicas autoritárias.

Nos países subdesenvolvidos, apesar da coesão entre os pobres permitir a existência do apoio mútuo em diversas situações, existem dificuldades para as intensificações das relações entre pobres e organizações executoras de políticas públicas, fazendo com que os governos atendam muito pouco às demandas da população de baixa renda. Nessas situações de carência de capital social entre grupos de posição social diferente, a população não participa ou pouco participa da vida pública. A eficiência do setor público é menor e este é mais permeável às pressões de grupos de interesse. É neste contexto de efetivação de uma sociedade pouco cívica que as redes de relações necessitam se organizar localmente em torno de um tema específico, como o da segurança alimentar. O processo de cristalização da segurança alimentar não ocorre no curto prazo, necessita da iniciativa governamental para ser alavancado.

Sem dúvida, a iniciativa do governante em nível municipal poderá facilitar a formação de uma rede de segurança alimentar. Ou seja, as relações de proximidade entre governo e cidadãos deverão contar significativamente para a cristalização da segurança alimentar em um município. Atores públicos municipais, especialmente do poder executivo, podem exercer papéis relevantes nos processos de coordenação de redes de segurança alimentar, através do estabelecimento de políticas públicas cujo objetivo seja o de potencializar as características das conexões em rede. Isto é, implementar regras mais claras e adaptadas à realidade local, facilitar a intensidade das relações dos atores envolvidos, expandir a velocidade dos programas e seus resultados, explorar a centralidade nas decisões para correções de etapas e

\footnotetext{
${ }^{6}$ Fukuyama (2002; p..231-237) reconhece que as redes devem se tornar mais importantes no mundo tecnológico do futuro, mas ressalva que há pelo menos três razões pelas quais a hierarquia permanecerá como parte necessária da organização no futuro previsível, contrariando, em parte, a afirmação de MANUEL CASTELLS, autor de TheRrise of Network Society, no qual declarou que estamos à beira de uma ampla mudança de hierarquia autoritária para redes e outras estruturas de poder radicalmente democratizadas. Suas razões são: “1. Não se pode dar como certa a existência de redes e seu capital social subjacente e, onde elas não existem, a hierarquia pode ser a única forma possível de organização. Na ausência de capital social, a organização hierárquica faz muito sentido e, de fato, pode ser a única maneira pela qual uma sociedade de baixa confiança pode se organizar; 2. a hierarquia com freqüência é fundamentalmente necessária para que organizações atinjam suas metas, pois há várias situações nas quais o controle hierárquico funciona de forma muito mais eficaz que o controle descentralizado. Embora uma rede possa ser mais inovadora pelo fato de colocar mais cérebros a trabalhar, assumir riscos e ver os resultados, há ocasiões em que a determinação de uma hierarquia centralizada é absolutamente essencial, e 3. as pessoas, por natureza, gostam de se organizar de forma hierárquica, sendo que por definição, as redes não tem líderes; exemplos e normas podem vir de baixo. Se as normas que criam capital social não existirem, a organização terá muito mais problemas para gerá-las internamente do que uma empresa que será organizada hierarquicamente sob um líder forte”
} 
metas dos programas, formalizar acordos necessários são elos de desenvolvimento.

Com estas ações é possível cristalizar nos atores envolvidos uma rede de segurança alimentar, sustentada no desenvolvimento do capital social local.

Nessa perspectiva, os efeitos deste tipo de coordenação em rede no Brasil (podendo envolver prefeituras municipais, empresas, grupos gestores, universidades, institutos de pesquisa, secretarias da administração pública, associações, sindicatos de agricultores e trabalhadores etc.) podem promover a formação da segurança alimentar local e, caso a agricultura familiar esteja inserida, também potencializar a economia do município, gerando emprego e renda.

\section{A concentração da agroindústria citrícola brasileira e as possibilidades de inclusão do suco de laranja natural no mercado institucional}

No transcorrer da década de 90 cerca de $17 \mathrm{mil}$ citricultores do Estado de São Paulo saíram da atividade, sendo que $80 \%$ destes eram pequenos produtores, motivados principalmente pela redução da demanda de laranja (Paulillo, 2000).

Isso é mais grave ainda porque $92 \%$ dos produtores de laranja sobreviventes no Estado de São Paulo são pequenos. E a distribuição da produção de laranja entre pequenos, médios e grandes citricultores nunca esteve tão desigual. A tabela 1 apresenta a distribuição da produção e dos pomares paulistas em relação ao tamanho da propriedade e mostra que apenas $1 \%$ dos citricultores paulistas é grande (possui mais de 100 mil árvores), mas representam cerca de $28 \%$ da produção, $7 \%$ dos produtores têm tamanho médio (possuem entre 20 a 100 mil pés em produção), mas representam 31\%

Tabela 1. Distribuição da Safra Paulista de Laranja - 2000/01.

\begin{tabular}{lcc}
\hline $\begin{array}{l}\text { Número de pés } \\
\text { em produção }\end{array}$ & $\begin{array}{l}\text { Produção } \\
\text { Total (\%) }\end{array}$ & $\begin{array}{c}\text { Número de } \\
\text { Produtores (\%) }\end{array}$ \\
\hline Até 20 mil & 41,0 & 92,0 \\
20 a 100 mil & 31,0 & 7,0 \\
Mais de 100 mil & 28,0 & 1,0 \\
\hline
\end{tabular}

Fonte: Almeida (2002) da produção, e a grande maioria (92\% dos citricultores) possui menos de 20 mil pés de laranja em produção e responde por cerca de $41 \%$ da produção total do Estado de São Paulo.

Isto é muito significativo, porque é na cadeia agroindustrial citrícola e no âmbito do processo de negociação entre empresas industriais e citricultores que estão enraizadas as dificuldades econômicas e sociais que os pequenos produtores e os trabalhadores rurais atravessam.

Se as grandes empresas processadoras de suco são as maiores compradoras das caixas de laranja e têm poder de barganha frente aos citricultores, elas podem coordenar o processo de formação dos preços da laranja na cadeia produtiva citrícola, beneficiando-se seja no mercado interno da matériaprima, seja no mercado internacional do suco concentrado, deixando em segundo plano os interesses dos citricultores (refletido principalmente no preço da caixa de laranja).

E como a grande indústria de processamento do suco (composta pelas 4 grandes empresas que sempre controlaram mais de $80 \%$ do suco concentrado de laranja brasileiro exportado) detém o poder de barganha ou de coordenação nesta cadeia produtiva? Primeiro adota a integração vertical para trás (da indústria para a citricultura). Operando com pomares próprios de laranja, as grandes processadoras podem contar, a cada safra, com um mínimo de $34 \%$ de pomares próprios, o que lhes garante quantidade suficiente para produzir e, ao mesmo tempo, aguardar o momento mais vantajoso para a compra da laranja de fornecedores (citricultores). Essa estratégia permite que a grande indústria reduza a demanda em qualquer momento (seja com oferta elevada seja com baixa), podendo forçar a queda do preço da caixa $(40,8 \mathrm{Kg})$. A tabela 2 indica o grau de integração vertical para trás do total das quatro grandes empresas processadoras de suco de laranja no Brasil, do grupo Montecitrus e dos grandes, médios e pequenos produtores independentes do setor.

Com menores preços pagos pela matéria-prima, a indústria brasileira de suco de laranja pode ofertar o produto no mercado internacional com preços mais baixos e competitivos que os grupos industriais de suco concorrentes de outros países. Assim, a conduta 
Tabela 2. Grau de Integração Vertical para Trás na Citricultura Brasileira - Pomares Citrícolas e Participação na Produção - 2004.

\begin{tabular}{lc}
\hline Grupos Empresariais & $\begin{array}{c}\text { Participação na } \\
\text { Produção (\%) }\end{array}$ \\
\hline Indústrias de Suco (4 C's) & 34,00 \\
Montecitrus e outras Empresas & 11,00 \\
Grandes Produtores Independentes & 34,00 \\
Pequenos e Médios Produtores & 21,00
\end{tabular}

Fonte: Souza Filho, H. M.; Paulillo, L. F. (2005)

estratégica de integração vertical da indústria para a citricultura, ao mesmo tempo em que proporciona elevação do poder de barganha industrial diante dos citricultores, não impede que seja observada outra condição estratégica fundamental para a indústria brasileira citrícola se manter como o maior competidor deste mercado global: a de garantia de abastecimento da matéria-prima num volume e qualidade compatíveis com a escala do setor no mundo.

Outra conduta estratégica industrial relevante neste contexto é a criação de estoques de suco concentrado congelado de laranja. O estoque é necessário para que o suco concentrado congelado de laranja esteja disponível para ser enviado aos compradores durante o ano todo, mas também permite a formação de um mecanismo de influência considerável na regulação do preço da referida commodity no mercado internacional e também no mercado interno. Com estoques elevados, as grandes processadoras podem retardar e até evitar a compra da laranja de determinadas variedades (pêra rio, hamlin, valência, natal, temporãs etc.), transformando-se em outro elemento determinante do poder de barganha da indústria diante da citricultura ${ }^{7}$.

Assim, as grandes empresas de suco que adotam formação de estoques podem forçar os citricultores a reduzir o preço. Em muitas safras, como a de 1999/ 2000 e a atual (2004/2005), o atraso das compras faz com que a maioria dos citricultores tenha a situação financeira agravada, o que pode levar à perda da produção ou ao abandono da atividade produtiva.
No caso de ocorrência de queda de demanda da caixa de laranja, as alternativas para os produtores seriam: a) venda para os intermediários ou barracões (que podem vender para comerciantes de fruta ou pequenas processadoras de outros Estados do país); b) venda para varejistas das regiões; c) venda direta para mercados in natura próximos da propriedade rural e d) perderem a venda da fruta. Este último aspecto já ocorreu em diversas safras, sendo que a de resultado mais acentuado foi na safra 1999/2000, na qual foram jogadas cerca de 40 milhões de caixas de laranja $(40,8 \mathrm{~kg})$.

Uma alternativa encontrada por uma parte de citricultores paulistas para tentar reduzir a queda do poder de barganha diante da indústria em cada negociação da safra é a adoção de grupos de comercialização. Mas esta alternativa é adotada com mais facilidade por grandes produtores, que possuem facilidade para organizarem grupos de venda (possuem mais informação, detêm maior conhecimento jurídico e contratual para vendas, têm maior volume de produção etc.) (Vieira, 2003, p. 59). A dificuldade de organização dos pequenos citricultores nos grupos (seja por preconceito ou por experiências negativas no passado e por falta de informação adequada sobre funcionamento de mercado e de questões contratuais e jurídicas) é o fator preponderante para que essa categoria esteja enfrentando um processo de exclusão nos últimos anos, quando a conduta estratégica industrial de integração vertical para trás se acentuou. A tabela 3 apresenta uma distribuição das formas de venda da laranja das diferentes categorias de produtores (\%) entre as safras 1998/99 e 2000/2001.

$\mathrm{Na}$ safra $98 / 99,84,6 \%$ dos pequenos, $90 \%$ dos médios produtores e $83,3 \%$ dos grandes venderam individualmente. Na safra 99/2000, 72,3\% dos pequenos venderam na forma individual e $27,7 \%$ venderam através de grupos, mostrando que houve um aumento da venda dos pequenos através dos pools, embora a maioria ainda vendesse individualmente. Os médios produtores, na safra 99/2000, também continuaram vendendo em sua maior parte individualmente, porém, como ocorreu com os pequenos, também houve um aumento da venda

\footnotetext{
7 “... estes estoques jogam um papel estratégico fundamental na medida em que a oferta de laranja é grande na safra e a quantidade exportada não registra grande aumento, é neste momento que as empresas acumulam para ganharem nas próximas safras, aproveitando dos preços baixos da laranja para comprar matéria-prima, processar e armazenar quantidades mais elevadas” (Vieira, 2003, p.70).
} 
Tabela 3. Formas de Venda da Laranja das diferentes categorias de produtores (\%) - dados referentes às safras 1998/99, $1999 / 2000$ e $2000 / 2001$.

\begin{tabular}{lccccccccc}
\hline \multirow{2}{*}{ Forma de vendas } & \multicolumn{3}{c}{ Pequenos (\%) } & \multicolumn{3}{c}{ Médios (\%) } & \multicolumn{3}{c}{ Grandes (\%) } \\
\cline { 2 - 10 } & $98 / 99$ & $99 / 00$ & $00 / 01$ & $98 / 99$ & $99 / 00$ & $00 / 01$ & $98 / 99$ & $99 / 00$ & $00 / 01$ \\
\hline Individual & 84,6 & 72,3 & 66,70 & 90,0 & 70,0 & 48,10 & 83,3 & 62,5 & 92,90 \\
Em grupo & 15,4 & 27,7 & 33,30 & 10,0 & 30,0 & 51,90 & 16,7 & 37,5 & 7,10 \\
Total & 100,0 & 100,0 & 100,0 & 100,0 & 100,0 & 100,0 & 100,0 & 100,0 & 100,0 \\
\hline
\end{tabular}

através dos pools. Entre os grandes produtores verificou-se o mesmo, ou seja, houve aumento da venda em grupo, embora a venda individual ainda fosse a predominante.

Já na safra 2000/2001, a tendência de aumento nas venda dos pequenos e médios produtores através de grupos ficou evidente. Enquanto que aproximadamente $34 \%$ dos pequenos produtores utilizaram esta forma de negociação, nos médios produtores esse valor foi superior a $50 \%$, constatando-se que os produtores estão buscando um maior poder de negociação frente à indústria processadora, que detém o poder econômico e político do complexo. Já os grandes produtores, detentores de altos poderes de barganha tendem a negociar individualmente.

O mercado institucional de laranja também é relevante na esfera do consumo citrícola nacional e pode ser um mecanismo importante para reduzir o perfil excludente do setor, principalmente se tomarmos como base os anos de maior excedente de laranja no Estado de São Paulo (1998 e 1999). Neste período, o excedente foi de cerca de 40 milhões de caixas. Estimativa de Paulillo (2000, p. 159) aponta para consumo anual do mercado institucional interno do Estado de São Paulo (educação infantil, ensino fundamental, ensino médio, educação de jovens e adultos e educação especial, hospitais e presídios) de cerca de 33 milhões de caixas de laranja para fornecimento de suco fresco (ou seja, transformado na hora do consumo), considerando consumo individual de 3 copos de $300 \mathrm{ml} /$ dia.

O Município de Bebedouro está inserido na macrorregião de Ribeirão Preto do Estado de São Paulo e tem, no setor agroindustrial citrícola, o eixo fundamental de desenvolvimento local, devido ao grande impacto das transações citrícolas no emprego e na renda da população do município e no desenvolvimento ambiental. As principais unidades produtivas industriais e agrícolas do município estão voltadas para produção, industrialização e comercialização da laranja e do suco concentrado congelado de laranja.

Sabe-se que o setor citrícola paulista está sofrendo um processo de reestruturação, com mudanças relevantes nas relações institucionais, de produção e de poder. Estas mudanças provocam impactos econômicos, políticos e ambientais e não geram necessariamente o desenvolvimento regional sustentável (Paulillo, 2000).

O setor agroindustrial citrícola tem, no Estado de São Paulo, suas produções agrícola e industrial realizadas no chamado cinturão citrícola, que abrange as antigas Divisões Regionais Agrícolas (DIRAs) de Sorocaba, Campinas, Ribeirão Preto, São José do Rio Preto e recentemente, uma parte da produção saltou o Rio Grande e encontra-se no sul de Minas, próxima ao Triângulo Mineiro. As partes mais importantes de suas produções agrícola e agroindustrial estão concentradas na região polarizada pelo município de Bebedouro (cerca de $60 \%$ da produção de laranja e $70 \%$ da produção de suco concentrado, respondendo por proporções iguais de emprego e renda).

Somente a microrregião de Bebedouro (abrangendo Monte Azul Paulista, Colina, Terra Roxa, Paraíso, Pirangi, Viradouro, além do próprio município de Bebedouro) apresenta atualmente cerca de 10.000.000 de pés em produção de laranja, distribuídos em mais de 1.000 propriedades, 4 empresas processadoras de suco concentrado (que concentram $40 \%$ da capacidade produtiva do Estado) e 20 packing houses (barracões de laranja), gerando aproximadamente 15 mil empregos diretos e 35.000 empregos indiretos no campo e na cidade (IEA, 2004). 
A agricultura familiar é predominante nos imóveis rurais dedicados à citricultura, principalmente nas pequenas e médias propriedades, pois representam $88 \%$ das propriedades até 100 hectares. Estas propriedades familiares congregam cerca de 3000 pessoas somente no município de Bebedouro, principalmente na fruticultura, e apresentam um bom nível de inserção tecnológica, mas sofrem um processo de marginalização nas grandes redes agroindustriais que pertencem.

O setor agroindustrial na microrregião de Bebedouro é de grande representatividade na cadeia citrícola paulista, tanto na produção de laranja como no processamento de suco concentrado, cuja produção é de mais de 10 milhões de pés em produção anuais. A produção da laranja ocorre fundamentalmente nas médias e grandes propriedades ( $75 \%$ da produção local), sendo que as pequenas propriedades, embora respondam por cerca de $70 \%$ do total de propriedades com pomares em atividade, produzem apenas $25 \%$ do total da produção de laranja local, gerando $35 \%$ do total dos empregos no município (IEA, 2004).

A região é bastante representativa no processamento de suco concentrado, pois nela estão localizadas 3 das maiores empresas do Brasil, que juntas podem processar 15 milhões de caixas/mês.

\section{O Programa "Frutos da Vida" em Bebedouro- SP: metodologia e caminhos da pesquisa}

O Programa Frutos da Vida consistiu em uma ação de política pública de segurança alimentar municipal, que visa distribuir suco de laranja fresco na merenda escolar para as crianças da rede municipal e estadual de ensino no município de Bebedouro-SP, tendo como fonte de matéria-prima a laranja comprada de pequenos e médios produtores de laranja do município, que se encontram em situação de exclusão. O projeto está articulado ao ideal de política local do Programa de Segurança Alimentar do Governo Federal, na medida em que busca proporcionar à população mais trabalho e melhor renda através da valorização da produção familiar, como também proporcionar a melhoria das condições de vida dos trabalhadores. Dois objetivos foram preponderantes: o primeiro deles é referente à qualidade do suco de laranja, uma vez que o suco deste projeto é fresco, passando apenas pelo processo de pasteurização; o segundo elemento refere-se à questão social, já que a laranja comprada para a fabricação do suco pertence a pequenos e médios produtores (que estão em dificuldades para escoar sua produção pelas vias tradicionais - indústria de suco e packing-house de fruta). Por fim, vale ressaltar que o referido programa tem a preocupação de gerar emprego e renda aos trabalhadores rurais, oferecendo salários superiores aos da categoria e garantindo todos os direitos trabalhistas.

Entre os municípios que compõem o cinturão citrícola paulista, Bebedouro se destaca pela quantidade de laranja plantada, de forma que a citricultura é de grande importância na economia do município. Contudo, desde os anos 90 este ramo de atividade vem apresentando dificuldades para os produtores de laranja, especialmente os pequenos e médios, de forma que a área plantada de laranja no município de Bebedouro e região vem sofrendo uma queda bastante considerável, com repercussões econômicas e sociais.

Neste sentido, o Programa Frutos da Vida tornou-se fundamental no espaço em que é desenvolvido, considerando que o complexo agroindustrial citrícola paulista se encontra em situação de concentração da produção de laranja (com os pomares próprios das indústrias e os contratos mais duradouros da indústria de suco com pools e grandes citricultores), tornando cada vez mais difícil a produção e comercialização em pequenas quantidades. O município de Bebedouro, tradicional produtor de laranja, vem sentindo a crise da citricultura e de seus citricultores, que cada vez mais cedem espaço para a cultura canavieira. Diante da situação de exclusão dos pequenos e médios produtores, que são os que encontram maiores dificuldades para vender a laranja para as indústrias de suco, o Programa Frutos da Vida ganha importância ao criar uma alternativa de venda para esses produtores e evitar que a citricultura seja reduzida ainda mais no município.

O suco de laranja natural, sem conservante, por ser uma forma de ingestão de vitamina $C$, deve ter seu consumo incentivado na sociedade e, neste sentido, esta política pública de segurança alimentar se torna um meio de tornar democrático o acesso da população carente à vitamina $C$, excelente 
produto para ser oferecido a crianças visando o seu pleno desenvolvimento físico.

Outro objetivo do programa foi o de oferecer merenda de qualidade aos alunos da rede escolar municipal e estadual, com nutrientes que possam colaborar para o desenvolvimento físico e intelectual dos alunos, enfrentando o problema de deficiência alimentar das crianças e adolescentes da rede de ensino público e, ao mesmo tempo, criar o hábito do consumo do suco de laranja.

Assim, desde o início o programa buscou abarcar os impactos sociais relacionados à produção de citros, proporcionando a oportunidade de inclusão de pequenos produtores rurais e aumentando o número de trabalhadores rurais. Enfim, está se criando no município de Bebedouro uma rede de capital social (cujos fatores de organização social são a cooperação, parceria, solidariedade e autenticidade da produção de laranja e do suco natural) e não apenas se mantendo uma cadeia de produção (na qual sempre prevaleceram mecanismos de exclusão, concentração produtiva, barreiras econômicas e políticas etc.).

Para que os objetivos fossem atendidos, ficou determinado: que todos os alunos das escolas do município receberiam suco diariamente; que a laranja fosse adquirida de pequenos e médios citricultores do município e região; que a colheita fosse realizada por trabalhadores registrados; que o suco fosse preparado por uma pequena fábrica e que essa produtora do suco respondesse pela entrega na central de abastecimento da prefeitura local (esta responsável pela embalagem, em saquinhos de $200 \mathrm{ml}$ ) e estocagem (suco condicionado em refrigeradores até a distribuição para as crianças).

O programa atendeu diariamente $14 \mathrm{mil}$ crianças da rede ensino das escolas municipais e estaduais, fornecendo a cada uma delas a unidade de $200 \mathrm{ml}$ de suco de laranja natural sem conservantes (perfazendo no total 320 mil litros de suco por ano). Cerca de 40 citricultores participaram do programa em 2004. No período da safra, seis trabalhadores rurais, com contrato permanente de trabalho, foram empregados na colheita e no transporte da laranja, recebendo salários integrais e não atrelados à produção diária. No período da entressafra, foram vinte e dois trabalhadores contratados com carteira assinada e garantia dos direitos trabalhistas.

A execução do projeto dependeu das elevadas freqüências dos contatos entre os agentes responsáveis pelo seu funcionamento, desde os produtores até os responsáveis pela distribuição do suco nas escolas. A rede objetivada teve início com as conexões entre prefeitura do município e citricultores por meio de negociação para a compra da laranja para a merenda escolar, sendo a colheita realizada pelos trabalhadores contratados; em seguida o processamento foi realizado por uma pequena fábrica do município e entregue na central de alimentação da prefeitura, responsável pelas atividades de empacotamento e distribuição nas escolas num prazo de 24 horas. Da colheita à distribuição, o prazo médio foi de 48 horas (visando conservar as características do suco natural até que este chegasse aos alunos).

Os indicativos de que os objetivos foram atendidos são dados pela melhoria na qualidade da merenda escolar na opinião de professores (40) e alunos (120) entrevistados, pela criação de um mercado alternativo aos citricultores e pela geração de renda para os trabalhadores rurais envolvidos na colheita.

O projeto foi desenvolvido pela prefeitura municipal de Bebedouro, em parceria com a Universidade Federal de São Carlos (UFSCar), contando com profissionais para a coordenação, o monitoramento e a fiscalização de campo (economistas, engenheiros de produção, um contador e uma pedagoga). Além da UFSCar, ocorreu uma parceria entre a prefeitura local e a empresa produtora do suco natural pasteurizado (Naturacitrus), além de envolver os departamentos municipais de agricultura, da educação, da saúde, de promoção social e a central de abastecimento popular local. Os recursos financeiros foram provenientes de verbas criadas pelo governo federal para gastos estritos com a educação fundamental (verba QESE - Quota Especial do SalárioEducação).

O desenvolvimento do projeto passou por uma fase inicial, que teve duração de cerca de seis meses, em que ocorreram os primeiros contatos 
Tabela 4. Síntese do programa de inserção do suco de laranja na merenda escolar do município de Bebedouro: atores envolvidos, quantidade total e custo médio do suco distribuído em 2004

\begin{tabular}{|c|c|}
\hline Atores públicos e privados participantes & $\begin{array}{l}\text { Prefeitura Municipal de Bebedouro, Secretaria da } \\
\text { Agricultura de Bebedouro, Secretaria da Educação de } \\
\text { Bebedouro, Secretaria da Saúde de Bebedouro, Universidade } \\
\text { Federal de São Carlos, Natura Citrus (empresa processadora } \\
\text { de suco), central de abastecimento popular do município. }\end{array}$ \\
\hline Atores coletivos participantes & $\begin{array}{l}\text { Associação dos Agricultores Familiares de Bebedouro, } \\
\text { Sindicato Rural de Bebedouro, Sindicato dos Trabalhadores } \\
\text { Rurais de Bebedouro, Casa da Agricultura de Bebedouro, } \\
\text { Associtrus (Associação dos Citricultores do Estado de São } \\
\text { Paulo), AMCISP (Associação dos Municípios Citrícolas do } \\
\text { Estado de São Paulo). }\end{array}$ \\
\hline Total de escolas e creches & 16 \\
\hline Crianças atendidas & 14.000 \\
\hline Número de citricultores envolvidos & 40 \\
\hline Trabalhadores rurais envolvidos (safra e entressafra) & 22 \\
\hline Quantidade produzida de suco de laranja (litros) & 320.000 \\
\hline Unidades (saquinhos $200 \mathrm{ml}$ ) & 1.600 .000 \\
\hline Dias de distribuição no ano & 200 \\
\hline Dias de entrega na semana & 3 \\
\hline Custo médio por litro de suco & $\mathrm{R} \$ 1,09$ \\
\hline Total de recursos financeiros & $\mathrm{R} \$ 350.000,00$ \\
\hline
\end{tabular}

Fonte: Pesquisa de Campo.

entre os agentes envolvidos e o agente coordenador (prefeitura local). Entre as principais ações estão o cadastramento dos produtores de laranja, as reuniões praticadas semanalmente e o estabelecimento de uma parceria com a empresa processadora do suco. A partir de sua implementação, o projeto funcionou sem interrupções durante o período letivo. A tabela 4 apresenta uma síntese em números do programa durante os períodos de safra e entressafra de 2004, quando a rede de capital social foi implementada. Deve-se destacar os atores sociais coletivos envolvidos, as crianças atendidas e o total de litros de suco de laranja que foram distribuídos, possibilitando a entrega de suco em grande parte do ano letivo.

A rede de capital social começou a se formar com o cadastramento dos citricultores interessados em participar do programa de inclusão de suco de laranja natural pasteurizado na merenda escolar. Após o cadastramento, as reuniões foram marcadas semanalmente pela prefeitura municipal (ator coordenador) com o objetivo de informar os procedimentos necessários para a participação dos interessados. Importa ressaltar que os citricultores necessitam desse tipo de informação rapidamente por causa do planejamento de venda da safra. A empresa processadora do suco, e que entrou como parceira da prefeitura municipal no programa por meio de concurso público (edital de licitação de preços), esteve presente desde as primeiras reuniões e facilitou a disseminação dos procedimentos e do estabelecimento de um cronograma para a compra da produção dos pequenos citricultores. As reuniões semanais possibilitaram transferir para os citricultores as informações necessárias para a participação no programa. 
As principais características estruturais da rede de capital social, que começou a se formar em 2003 e 2004 em torno da citricultura e da merenda escolar de Bebedouro, estão apresentadas sinteticamente na tabela 5. Os pesos apontados para cada uma dessas características foram atribuídos pelos atores participantes do programa durante a aplicação de um questionário estruturado em pesquisa de campo.

No plano das relações estruturais da rede, as regras estabelecidas para o funcionamento do programa e a centralidade das decisões pela prefeitura municipal foram as mais relevantes desde o começo do processo de inserção do suco na merenda. Conseqüentemente, a velocidade das decisões tomadas pelos atores públicos e privados foi um fator que pesou favoravelmente, tornando o programa funcional e ágil no contorno de problemas do dia a dia (distribuição rápida do suco, adaptação das merendeiras, busca da laranja nas propriedades rurais, armazenamento do suco em câmaras frias etc.). Assim, as dependências de rota puderam ser aperfeiçoadas segundo os interesses da prefeitura municipal em garantir a entrega regular do suco nas escolas, e para isso os produtores de laranja tiveram garantia de pagamento sem atrasos.

As regras foram colocadas rapidamente pela prefeitura, que logo nos primeiros contatos com os atores produtivos interessados informou a todos sobre os procedimentos legais e jurídicos que eram necessários para este tipo de transação entre ator público e privado (licitação de preços, carta convite ou leilão). A centralização deste programa sempre foi intensa, pois a prefeitura teve que ser a responsável legal por todos os atos relacionados à transação dos frutos e também do processamento do suco. Uma particularidade da centralização do processo de desenvolvimento da rede foi a de que a prefeitura necessitou de assessoria especial de uma universidade pública para a coordenação, posto que os agentes produtivos (principalmente os citricultores) não tinham qualquer conhecimento do modo de organização em rede com componentes definidos de cooperação e segurança alimentar (atentada para os eixos da saúde, higiene, solidariedade, autenticidade e meio ambiente), do funcionamento dos processos de compra e venda entre prefeitura municipal e citricultores do município, além de a maioria estar totalmente alijada de informações vitais do mercado de laranja no país e no exterior (formação dos preços, atualização dos custos de produção etc.) e da dinâmica do complexo agroindustrial citrícola (com seus canais de suprimentos fortemente coordenados e uma rede política totalmente controlada pelas grandes empresas processadoras - as 4 C's).

As reuniões foram semanais nos primeiros seis meses e, depois, passaram a ser quinzenais. Isso significa que, desde o começo, a velocidade das conexões teve importância, e a intensidade dos contatos, apesar de ser mais significativa no começo da constituição da rede, também contribuiu para o interesse comum da rede (isto é, fornecimento regular de suco nas escolas, seguindo o interesse principal da prefeitura, e pagamento em dia das caixas de laranja vendidas, seguindo o interesse principal dos citricultores locais). Durante todo o processo, os contatos mais informais entre os agentes foram um dos pilares de sustentação da rede, com as equipes dos técnicos da prefeitura municipal e de assessoria da universidade pública buscando os produtores constantemente em suas propriedades para passar informações e orientar sobre os processos de transação da laranja e a possível formação de uma associação de pequenos citricultores do município. A empresa processadora de suco, por estar envolvida no setor e também conhecer muitos citricultores locais há um tempo considerável, também colaborou para o funcionamento da rede com a intensificação de contatos informais e no fechamento de muitas transações.

Desde o início da formação da rede desenvolveu-se o processo de transferência de conhecimento entre os atores (prefeitura municipal, equipe universitária assessora do programa, equipe da secretaria agrícola, empresa de processamento, produtores de laranja, professores e diretores de escolas). As principais transferências deram-se nos seguintes pontos: formação de preços nos mercados tradicionais da cadeia citrícola no Brasil e no mundo (para laranja e para sucos concentrado e natural pasteurizado); aprendizagem de formulação de planilhas de custos de produção; cursos de capacitação para citricultores e trabalhadores rurais; formação de pools de venda para a prefeitura; condução de consórcios de produtores rurais, formação de uma associação municipal de citricultores.

Por fim, deve-se salientar que a reputação do ator-coordenador da rede (a prefeitura municipal de Bebedouro) foi desenvolvida durante a constituição do 
Redes de segurança alimentar e desenvolvimento local, Paulillo et al.

Tabela 5. Caracterização da rede de capital social da pequena citricultura de Bebedouro-SP.

\begin{tabular}{|c|c|c|c|}
\hline Características dos membros & Peso & Características das conexões & Peso \\
\hline 1. Transferência de informação & $* * *$ & 1. Regras & $* * * * *$ \\
\hline 2. Legitimidade & $* * * * *$ & 2. Centralidade & $* * * * *$ \\
\hline 3. Reputação & $* * * *$ & 3. Intensidade & $* * *$ \\
\hline 4. Cooperação & $* * * *$ & 4. Velocidade & $* * * * *$ \\
\hline 5. Transparência & $* * * * *$ & 5. Informalidade dos contatos & $* * * *$ \\
\hline
\end{tabular}

Legenda: Muito Forte $\left({ }^{* * * *}\right)$; Forte $\left({ }^{* * * *}\right)$; Regular $(* * *)$; Fraco $(* *)$; Muito Fraco $\left(^{*}\right)$.

Fonte: pesquisa de campo.

programa de inserção do suco de laranja na merenda escolar local, porque nos primeiros meses de 2003 os próprios citricultores lançavam dúvidas sobre o comprometimento da prefeitura com a consolidação do programa, já que envolvia dispêndios por parte deste ator público, tradicional lançador de calotes em pagamentos de fornecedores da prefeitura (isto é, no início a reputação do coordenador do programa estava abalada, um fator que poderia comprometer o bom andamento da rede). Posteriormente, com o andamento do programa e as ocorrências de pagamentos regulares aos citricultores, a reputação da prefeitura como coordenadora da rede começou a mudar. Os envolvimentos da prefeitura municipal na organização das reuniões com os produtores de laranja (alijados de qualquer processo decisório no complexo agroindustrial citrícola brasileiro, porque a rede política formada é totalmente coordenada pelas $4 \mathrm{C}^{\prime} \mathrm{s}$ ), no programa da merenda escolar, na formação de uma associação de pequenos citricultores e no cumprimento diário dos pagamentos aos citricultores foram fatores determinantes da elevação da reputação da prefeitura junto aos demais participantes do programa. A legitimidade da rede formada foi alcançada pela elevação da reputação da entidade coordenadora do programa (prefeitura municipal), freqüência das transações e formação de uma associação, junto com um grande pool de venda de caixas de laranja, reavaliação constante dos preços junto ao mercado tradicional e com o envolvimento de uma universidade pública (assessorando e dando credibilidade ao programa).

\section{Considerações Finais}

Um encadeamento agroalimentar não é igual ao outro. Em cada um deles atuam diferentes atores que se movimentam dentro das características dadas pela cultural local, pelo ambiente institucional e pelas expectativas econômicas. Isso significa que a operação de políticas públicas para cada caso requer soluções diferenciadas. (Belik \& Maluf, 2000, p. ix). Essas soluções tornam-se mais específicas naqueles encadeamentos agroindustriais que operam regionalmente, porque eles formam campos organizacionais em que a proximidade dos atores, a cultura e a história local podem facilitar as decisões de índole política. Isto é, o surgimento de uma nova estrutura de oportunidades é possível com a maior participação dos atores localizados no desenho do futuro coletivo territorial.

A proximidade dos atores pode facilitar a implementação de políticas que contemplem as especificidades do food security e do food safety, preservando assim o caráter justo e democrático da produção e distribuição agroalimentar. Isso não é possível com políticas direcionadas apenas para os encadeamentos agroindustriais nacionais e/ou globais, mas sim para seus campos organizacionais localizados (em estados, regiões, associações de municípios etc.). A formação de uma rede de capital social vinculada à produção de laranja e distribuição de suco na merenda escolar de um município citrícola do estado de São Paulo (Bebedouro) mostrou que é possível concretizar um estágio de segurança alimentar local que abarque valores nutricionais dos alimentos, autenticidade de produtos, saúde das pessoas e solidariedade a produtores agrícolas e trabalhadores rurais marginalizados em um complexo agroindustrial 
(como o citrícola brasileiro). Além disso, esse processo pode mostrar o início da cristalização (embeddedeness) de uma rede de capital social (envolvendo características sociais positivas dos indivíduos - cooperação, transparência, reputação, legitimidade - e características positivas das relações sociais em rede - freqüência, intensidade, velocidade etc.).

Alguns aspectos de ordem geral abarcam a questão da especificidade dos campos organizacionais agroindustriais regionalizados. São eles: 1) viabilização da pequena propriedade agrícola, locus da produção doméstica, e da melhoria das condições de trabalho rural, com condições estruturais para o seu desenvolvimento; 2) estímulo às micro e pequenas processadoras em consórcios e distritos agroindustriais; 3) coordenação de fluxos produtivos de alimentos básicos para o mercado institucional (escolas, creches, hospitais, penitenciárias etc.); 4) fomento à produção de bens agrícolas domésticos ou de hábitos alimentares locais/regionais; 5) criação e viabilização de assentamentos rurais que privilegiem as vantagens comparativas da agricultura local/regional.

Assim, os processos de reestruturação agroindustrial no Brasil não devem ser vistos simplesmente como adaptações flexíveis a problemas globais. As localidades os especificam, porque reagem de forma diferenciada e podem influenciá-los. Este trabalho mostrou que redes locais podem operar de modo distinto quando direcionados para a segurança alimentar. Os padrões institucionais, normas e valores sociais próprios de cada localidade sinalizam uma capacidade de estabelecimento de pautas de desenvolvimento social de caráter inovador no Brasil, desde que os processos de reestruturação não apresentem um caráter estritamente econômico, mas envolvam decisões de índole política e o desenvolvimento do capital social localizado. Assim, características de organização social, como confiança, normas e redes podem facilitar os processos de ação coordenada e a provisão de bens públicos, como a segurança alimentar.

\section{Referências Bibliográficas}

ALMEIDA, L. M. Novas Formas de Contratação de Mão-de-obra Rural no Complexo Agroindustrial Citrícola Paulista. São Carlos: UFSCAr, 2002. Dissertação (Mestrado em Engenharia de Produção), Centro em Ciências Exatas e Tecnológicas.

ARAÚJO, M. C. S. Capital Social - Rio de Janeiro: Jorge Zahar Ed., 2003.

ARCE, A; MARSDEN, T. Food practices and social relations: towards cultures of consumption. Paper presented at the XIIIth World Congress of Sociology, Bielfeld. 1994.

BELIK, W.; MALUF, R. (orgs.) Abastecimento e segurança alimentar: os limites da liberalização. Campinas; IE/UNICAMP, 2000. 234 p.

BONANNO, A; MARSDEM, T.; SILVA, J. F. G. "Globalização e localização: elementos para entender a reestruturação dos espaços rurais". In: Cavalcanti, J. S. B. (Org.) Globalização, trabalho, Meio ambiente: mudanças socioeconômicas em regiões frutícolas para exportação. Recife: Editora Universitária da UFPE, 1999.

BOURDIEU, Pierre. Le capital social. Actes de la recherche en sciences sociales. Paris, n.31, 1980.

CASTILHOS, D.S.B. Capital social e políticas públicas: um estudo da linha infra-estrutura e serviços aos municípios do Programa Nacional de Fortalecimento da Agricultura Familiar: Porto Alegre: UFRGS/IEPE/ PGDR, Dissertação de Mestrado, 2001.

CASTELL, M. The Rise Of Network Society The Information Age: Economy, Society and Culture - Vol. 1. Cornwall, Grã Bretanha: Blackwell, Publishers, 1996/1998.

COLEMAN, James S. Foundations of Social Theory - Cambridge, Londres: The Belknap Press of Harvard University Press , 1990.

DOWDING, K. Model or metaphor? A critical review of the policy network approach. Oxford: Blackwell Publisher. Political Studies, n. XLII, 1995.

FRIEDMAN, H. Uma economia mundial de alimentos sustentável. In: Belik, W. ; Maluf, R. S. Abastecimento 
e segurança alimentar: os limites da liberalização. Campinas: IE/UNICAMP, 2000. p. 01-22.

FUKUYAMA, Francis. A grande ruptura: A Natureza Humana e a Reconstituição da Ordem Social. Rio de Janeiro: Rocco, 2000.

INSTITUTO DE ECONOMIA AGRÍCOLA Perfil Agrícola dos Municípios Paulistas - 2004. Secretaria da Agricultura e do Abastecimento do Estado de São Paulo. Disponível em (www.iea.sp.gov.br).

MONASTERIO, L. M. Putnam no Pampa: Capital Social e a Metade Sul do Rio Grande do Sul. Anais do II Seminário da Nova Economia Institucional. Campinas, IE/UNICAMP, julho/ 2001, CD-ROM.

MALUF, R. S.; MENEZES, F.; VALENTE, F. Contribuição ao tema da segurança alimentar no Brasil. Cadernos de Debate, NEPA/UNICAMP, Campinas, vol. IV, p. 66-88, 1996.

ORTEGA, A. C. Acción colectiva y articulación de intereses en los complejos agroindustriales brasileños: organizaciones especializadas por productos e interprofesiones. Córdoba: Universidade de Córdoba, 1995. Tese (doutorado em Economia), Departamento de Economia, Sociologia e Política Agrária.

PAUlillo, L. F. Redes de Poder e Territórios Produtivos. São Carlos: Ed. UFSCAr, 2000.
PAULILLO, L. F. et al. Reestruturação agroindustrial, políticas públicas e segurança alimentar regional. São Carlos: Edufscar, 2002.

PAULILLO, L. F.; PESSANHA, L. Segurança alimentar, políticas públicas e regionalização: In: PAULILLO, L. F. et. al. Reestruturação agroindustrial, políticas públicas e segurança alimentar regional. São Carlos: Edufscar, 2002.

PUTNAM, Robert D. Comunidade e Democracia: a experiência da Itália Moderna. Rio de Janeiro: Fundação Getúlio Vargas, 1996.

PUTNAM, Robert D. Bowling Alone. Touchstone, Rockefeller Center, USA, 2000.

SABOURIN, Eric - Planejamento do Desenvolvimento dos Territórios Rurais Conceitos, controvérsias e experiências - Brasília : UFPB/CIRAD/EMBRAPA, 2002.

SOUZA FILHO, H. M.; PAULILlO, L. F. Public policies, transaction costs and access to commodity chain markets - Brazil. Roma: FAO/ ONU. Relatório de pesquisa, 2005.

VIEIRA, A.C. Integração Vertical, Concentração e Exclusão na Citricultura Paulista.. 171 p. (Doutorado em Engenharia de Produção). Centro de Ciências Exatas e Tecnologia, Universidade Federal de São Carlos, São Carlos, 2003, 